\title{
Differentially expressed mRNAs, proteins and miRNAs associated to energy metabolism in skeletal muscle of beef cattle identified for low and high residual feed intake
}

Elisa B. Carvalho ${ }^{1,2}$, Mateus P. Gionbelli ${ }^{1}$, Rafael T. S. Rodrigues ${ }^{2,3}$, Sarah F. M. Bonilha ${ }^{4}$, Charles J. Newbold ${ }^{5}$, Simone E. F. Guimarães ${ }^{2}$, Walmir Silva², Lucas L. Verardo ${ }^{6}$, Fabyano F. Silva², Edenio Detmann² and Marcio S. Duarte $2^{2^{*}}$

\begin{abstract}
Background: Feed efficiency is one of the most important parameters that affect beef production costs. The energy metabolism of skeletal muscle greatly contributes to variations in feed efficiency. However, information regarding differences in proteins involved in the energy metabolism of the skeletal muscle in beef cattle divergently identified for feed efficiency is scarce. In this study, we aimed to investigate energy metabolism of skeletal muscle of Nellore beef cattle, identified for low and high residual feed intake using a proteomics approach. We further assessed the expression of candidate microRNAs as a one of the possible mechanisms controlling the biosynthesis of the proteins involved in energy metabolism that were differentially abundant between high and low residual feed intake animals.

Results: A greater abundance of 14-3-3 protein epsilon $(P=0.01)$ was observed in skeletal muscle of residual feed intake (RFI) high animals (RFI-High). Conversely, a greater abundance of Heat Shock Protein Beta $1(P<0.01)$ was observed in the skeletal muscle of RFI-Low cattle. A greater mRNA expression of YWHAE, which encodes the 14-3-3 protein epsilon, was also observed in the skeletal muscle of RFI-High animals $(P=0.01)$. A lower mRNA expression of HSPB1, which encodes the Heat Shock Protein Beta 1, was observed in the skeletal muscle of RFI-High animals $(P=0.01)$. The miR-665 was identified as a potential regulator of the 14-3-3 protein epsilon, and its expression was greater in RFI-Low animals $(P<.001)$. A greater expression of miR-34a $(P=0.01)$ and miR-2899 $(P<.001)$ was observed in the skeletal muscle of RFI-High animals, as both miRNAs were identified as potential regulators of HSPB1 expression.

Conclusion: Our results show that Nellore cattle divergently identified for feed efficiency by RFI present changes in the abundance of proteins involved in energy expenditure in skeletal muscle. Moreover, our data point towards that miR-665, miR34a and miR-2899 are likely involved in controlling both 14-3-3 epsilon and HSPB1 proteins identified as differentially abundant in the skeletal muscle of RFI-High and RFI-Low Nellore cattle.
\end{abstract}

Keywords: Bovine, Feed efficiency, Muscle biology, Nellore, Proteomics

\footnotetext{
* Correspondence: marcio.duarte@ufv.br

${ }^{2}$ Department of Animal Science, Universidade Federal de Viçosa, Viçosa, MG,

Brazil

Full list of author information is available at the end of the article
}

(c) The Author(s). 2019 Open Access This article is distributed under the terms of the Creative Commons Attribution 4.0 International License (http://creativecommons.org/licenses/by/4.0/), which permits unrestricted use, distribution, and reproduction in any medium, provided you give appropriate credit to the original author(s) and the source, provide a link to the Creative Commons license, and indicate if changes were made. The Creative Commons Public Domain Dedication waiver (http://creativecommons.org/publicdomain/zero/1.0/) applies to the data made available in this article, unless otherwise stated. 


\section{Background}

Feed efficiency is one of the most important parameters affecting beef production costs. Residual feed intake (RFI) has been suggested as a more suitable trait for animal selection than the feed conversion ratio [1], as it is phenotypically independent of growth rate and body weight in growing cattle [2-4]. Although RFI has been extensively used to evaluate feed efficiency [5], its physiological and/or metabolic bases remain unclear. According to Herd and Arthur [6], at least five major processes are involved in the variation of efficiency: feed intake, feed digestion, animal activity, thermoregulation, and energy metabolism.

The turnover of body proteins accounts for $30 \%$ of energy expenditure in cattle maintenance. The metabolism of skeletal muscle represent an important factor regulating feed efficiency, since this tissue, together with liver tissue, account for around two-thirds of the whole body protein turnover in mammals [7]. However, most studies regarding molecular mechanisms underlying differences in feed efficiency in beef cattle have focused their efforts on changes at the transcriptome level [8-12], while information regarding differences at the proteomic level is scarce. Additionally, studies in cattle have suggested the role of microRNAs (miRNA) on feed intake at the post-transcriptional level $[13,14]$ and should be considered in further studies.

The miRNAs are a class of noncoding RNAs expressed in several eukaryotic organisms [15]. They are about 20 nucleotides (nt) long and regulate translation by binding to the 3' untranslated region of their targets genes $[15,16]$. Important roles of miRNAs in the gene-regulatory of numerous eukaryotic lineages have been reported [17]. Moreover, there is evidences of miRNAs related with feed efficiency and energy metabolism in pigs [18] and cattle [14], highlighting the importance of miRNAs in energy metabolism and, consequently, changes in feed efficiency.

We have hypothesized that Nellore cattle divergently identified for feed efficiency by RFI differ in energy expenditure in skeletal muscle. Therefore, our objective was to investigate the skeletal muscle proteomic profile of beef cattle diverging on RFI, aiming to identify key proteins that indicates difference in energy expenditure. We further assessed the expression of miRNAs as one of the possible post-transcription mechanisms controlling the expression of these proteins.

\section{Methods}

Care and handling of all experimental animals were conducted under protocols approved by the Ethics Committee on Animal Use of the Instituto de Zootecnia (CEUA/ IZ; Protocol 213-15), Nova Odessa, SP, Brazil, and in accordance with guidelines of State Law No. 11.977 of the State of São Paulo, Brazil.

\section{Animals and experimental diet}

A contemporary group of 129 young Nellore bulls [seven months of initial age and $239 \pm 30.1 \mathrm{~kg}$ of initial body weight $(\mathrm{BW})$ ] were subjected to a growth period of 98 days receiving the same diet formulated to meet the requirements for $1 \mathrm{~kg} / \mathrm{d}$ of BW gain (Table 1 ). Cattle were fed using a GrowSafe ${ }^{\bullet}$ automated feeding system (GrowSafe ${ }^{\oplus}$ Systems Ltd., Airdrie, Canada). The RFI (kg/ day) was calculated after the growth period test using the following model:

$$
\mathrm{FI}=\beta_{0}+\beta_{\mathrm{P}} \times \mathrm{BW}^{0.75}+\beta_{\mathrm{G}} \times \mathrm{ADG}+\varepsilon(\mathrm{RFI}),
$$

where $\mathrm{FI}=$ estimated daily feed intake $(\mathrm{kg} /$ day $), \beta_{0}=$ regression intercept, $\beta_{\mathrm{P}}=$ partial regression coefficient of FI on average metabolic weight, $\mathrm{BW}^{0.75}=$ metabolic body weight $(\mathrm{kg}), \beta_{\mathrm{G}}=$ partial regression coefficient of FI on average daily gain (ADG, $\mathrm{kg} /$ day) and $\varepsilon=$ residual error (RFI, kg/day).

From the 129 animals used in the growth period, a total of 18 Nellore bulls [nine with the lowest $(-1.18 \pm$ $0.44)$ or highest $(1.20 \pm 0.46)$ estimated RFI] were selected, with a final age and BW of $22.5 \pm 0.8$ months and $401 \pm 42 \mathrm{~kg}$, respectively. Each selected animal was considered an experimental unit. All animals were confined in individual pens (measuring $4 \times 2 \mathrm{~m}$ ) with ad libitum access to water and diet. Feeding management was performed using the GrowSafe ${ }^{\bullet}$ automated feed

Table 1 Ingredient and chemical composition of experimental diets

\begin{tabular}{lll}
\hline Item & Growth period & Finishing period \\
\hline Ingredient, g/kg & 615 & 333 \\
Corn silage & 33.0 & 17.0 \\
Brachiaria hay & 167 & 465 \\
Dry-ground corn & 163 & 163 \\
Soybean meal & 18.0 & 13.0 \\
Mineral premix & 3.60 & 6.00 \\
Urea & 0.40 & 4.00 \\
Ammonium sulfate & & \\
Composition, g/kg of DM & 496 & 636 \\
Dry matter, g/kg & 937 & 946 \\
Organic matter & 137 & 134 \\
Crude protein & 594 & 646 \\
Neutral detergent fiber & 25.0 & 32.1 \\
Ether extract &
\end{tabular}

a Provided (per kg of DM): $140 \mathrm{~g}$ of $\mathrm{Ca}, 137.2 \mathrm{~g}$ of $\mathrm{Na}, 12 \mathrm{~g}$ of $\mathrm{S}, 80 \mathrm{~g}$ of $\mathrm{P}$, $4,500 \mathrm{mg}$ of $\mathrm{Zn}, 1,400 \mathrm{mg}$ of $\mathrm{Mn}, 11 \mathrm{mg}$ of $\mathrm{Ni}, 1,600 \mathrm{mg}$ of $\mathrm{Cu}, 210 \mathrm{mg}$ of $\mathrm{Co}$, $180 \mathrm{mg}$ of $\mathrm{l}, 27 \mathrm{mg}$ of $\mathrm{Se}$, and $800 \mathrm{mg}$ of $\mathrm{F}$ 
system (Growsafe Systems Ltd., Airdrie, Alberta, Canada). The 18 selected animals were weighed, vaccinated, and dewormed at the beginning of the fishing period. Cattle were adapted to the diets, facilities, and management for $22 \mathrm{~d}$ and fed the finishing diet for a 103- $\mathrm{d}$ period. The finishing diet was composed of $333 \mathrm{~g} /$ $\mathrm{kg}$ corn silage, $17 \mathrm{~g} / \mathrm{kg}$ brachiaria hay, $465 \mathrm{~g} / \mathrm{kg}$ dry ground corn, $163 \mathrm{~g} / \mathrm{kg}$ soybean meal, $6 \mathrm{~g} / \mathrm{kg}$ urea, $4 \mathrm{~g} / \mathrm{kg}$ ammonium sulfate, and $13 \mathrm{~g} / \mathrm{kg}$ mineral mixture (dry matter basis), and were formulated to meet the requirements of $1.3 \mathrm{~kg}$ of daily gain with a target finish weight of $550 \mathrm{~kg}$. Both RFI-High and RFI-Low groups were fed the same diet and kept under the same conditions throughout the finishing period. More details about the herd characterization, performance, carcass traits, and meat quality evaluations for these animals can be found in Fidelis et al. (2017) [19]. Details about the energy metabolism in the rumen epithelium of these animals can be found in a previous study [20] carried out by our research group.

\section{Animal slaughter and skeletal muscle tissue collection}

At the end of the performance trial, bulls were transported to an experimental slaughterhouse abattoir for slaughter. Pre-harvest handling was conducted in accordance with good animal welfare practices, and slaughtering procedures followed strict guidelines established and regulated by the Sanitary and Industrial Inspection Regulation for Animal Origin Products [21]. Longissimus muscle was sampled immediately after exsanguination at the 12th rib of the right side of the carcass. Once collected, skeletal muscle tissue samples were immediately placed in liquid nitrogen then transported to the laboratory. Once samples arrived at the laboratory, they were powdered in liquid nitrogen using a mortar and pestle. Samples were then placed in a cryogenic tube and stored in liquid nitrogen until extraction of proteins, total RNA, and miRNA.

\section{Total protein extraction}

Samples of skeletal muscle tissue $(0.05 \mathrm{~g})$ were homogenized using a polytron PT 3100 (Lucerne, Switzerland) on ice for $10 \mathrm{~s}$ in $1 \mathrm{~mL}$ of lysis buffer containing: $7 \mathrm{M}$ urea, $2 \mathrm{M}$ thiourea, 4\% 3-3 [(cholamidopropyl) dimethylammonium] -1- propanesulfonate (CHAPS), 1\% dithiothreitol (DTT), 2\% immobilized $\mathrm{pH}$ gradient (IPG) buffer (pH 3 to 10), $1 \mathrm{M}$ phenylmethanesulfonyl fluoride (PMSF) and protease inhibitors. The supernatant was obtained after centrifugation at 10,000 $\mathrm{x} g$ for $30 \mathrm{~min}$ at $4{ }^{\circ} \mathrm{C}$ was used as the protein extract for later electrophoresis analysis. The total amount of proteins was quantified by Quick Start Bradford Protein Assay (BioRad, Hercules, CA) using Bovine serum albumin (BSA) as a standard. The total proteins extract was separated by SDS-PAGE $10 \%$ gel by loading with $80 \mu \mathrm{g}$ of protein per sample for quality control to check protein integrity.

\section{Two-dimensional electrophoresis}

In the first dimension of electrophoresis, the Immobilized $\mathrm{pH}$ Gradient (IPG) strips (GE Healthcare Lifesciences, Uppsala, Sweden) of $24 \mathrm{~cm}, \mathrm{pH} 3-10$, were rehydrated overnight at room temperature in $450 \mu \mathrm{l}$ of DeStreak rehydration solution (GE Healthcare Lifesciences, Uppsala, Sweden) and 2\% IPG buffer pH 3-10, containing $1200 \mu \mathrm{g}$ of protein. The, samples were then subjected to isoelectric focusing on an Ettan IPGphor3 system (GE Healthcare Lifesciences, Uppsala, Sweden) at $20^{\circ} \mathrm{C}$ for the specific type of IPG strip (step and hold at $500 \mathrm{~V}$ for $1 \mathrm{~h}$; gradient to $1000 \mathrm{~V}$ for $0.8 \mathrm{kVh}$ gradient to $10,000 \mathrm{~V}$ for $16.5 \mathrm{KVh}$, and step at $10000 \mathrm{~V}$ for 17.2 $\mathrm{KVh}$ ), with a current limit of $50 \mathrm{~mA} /$ strip.

For the second dimension, strips were equilibrated in $1.5 \mathrm{M}$ Tris- $\mathrm{HCl}$ (pH 8.8), $6 \mathrm{M}$ urea, $2 \%$ sodium dodecyl sulfate (SDS), $30 \%$ glycerol, and $0.002 \%$ bromophenol blue buffer for $20 \mathrm{~min}$ with $1 \%$ dithiothreitol (DTT) followed by $20 \mathrm{~min}$ with $2.5 \%$ iodoacetamide. The strips were transferred to a $12.5 \%$ acrylamide gel and fixed with an agarose sealing solution. The SDS-polyacrylamide gel electrophoresis (SDS-PAGE) was performed in a vertical Ettan DALTsix system (GE Healthcare Lifesciences, Uppsala, Sweden) using a Laemmli running buffer at $1 \times$ concentration for the anode and $2 \times$ concentration for the cathode. The electrical current for electrophoresis was kept at $20 \mathrm{~mA} /$ gel with an initial voltage of $80 \mathrm{~V}$ for 45 min to allow proteins to migrate from the gel strip into the polyacrylamide gel. After this period, the voltage was increased to $500 \mathrm{~V}$, using $40 \mathrm{~mA} /$ gel until the sample ran to the end of the gel. At the end of the run, gels were stained using a colloidal Coomassie Blue G-250 procedure, involving fixation in $10 \%$ acetic acid $/ 40 \%$ ethanol overnight followed by addition of a solution containing $8 \%$ ammonium sulfate, $0.8 \%$ phosphoric acid, 0.08\% Coomassie Blue G-250, 20\% methanol for $72 \mathrm{~h}$, and de-stained by a solution of acetic acid at $1 \%$. Finally, gels were kept in a solution of $2 \%$ acetic acid until subsequent image analysis.

\section{Image analysis}

The two-dimensional electrophoresis (2-DE) gels were scanned with ImageScanner III (GE Healthcare BioSciences, Uppsala, Sweden), using the Lab Scan program (GE Healthcare Lifesciences, Uppsala, Sweden) and analyzed by using ImageMaster Platinum software (GE Healthcare Lifesciences, Uppsala, Sweden).

\section{In-gel digestion of proteins}

The differentially abundant spots between the two extremes for RFI were cut out from the gels and placed in 
$1.5 \mathrm{~mL}$ tubes. Trypsinization was performed using a modified method based on Shevchenko et al. (2006). The gels pieces were destained through washes with a solution containing $50 \%$ acetonitrile $(\mathrm{ACN})$ and $25 \mathrm{mM}$

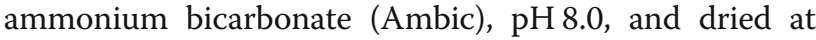
room temperature. Subsequently, the solution was removed and samples were dehydrated in $100 \% \mathrm{ACN}$ $(200 \mu \mathrm{l})$. The reduction reaction was made with $100 \mu \mathrm{l}$ of $65 \mathrm{mM}$ DTT and $100 \mathrm{mM}$ Ambic and alkylation was made with $100 \mu \mathrm{l}$ of $200 \mathrm{mM}$ iodoacetamide and 100 $\mathrm{mM}$ Ambic. For sample cleavage, $20 \mu \mathrm{l}$ of Porcine Trypsin (Mass Spectrometry Grade, Promega, Madison, USA) was added to the fragments and kept on ice for $45 \mathrm{~min}$, to allow trypsin to penetrate the gel fragments. Recovery of the tryptic peptides was made through the addition of a solution containing 5\% formic acid and $50 \% \mathrm{ACN}$ and removal of the supernatant. Samples were desalted using Zip Tip C18 micro columns (Millipore, Billerica, MA) to decrease interference from crystallization of the samples with the matrix used in a mass spectrometer analysis, and were then stored at $-20^{\circ} \mathrm{C}$ until subsequent analysis.

\section{Protein identification}

Peptide masses of the samples were obtained using an Ultraflex III MALDI TOF/TOF mass spectrometer (Bruker Daltonics, Bremen, Germany) and then screened against the Bovidae database deposited in UniProt using the MASCOT program (Matrix Science, London, UK) and a MASCOT Peptide Mass Fingerprinting database search. An accuracy of $0.5 \mathrm{Da}$ was used in the search criteria. Trypsin was set as an enzyme with one allowed miscleavage. The fixed modification and variable modification factors used were carbamidomethyl and oxidation, respectively. The numbers of peptide matches, sequence coverage, molecular weight (MW), and isoelectric point (pI) were used to evaluate the database search results. The Scaffold program (Proteome Software, Portland, OR) was used to validate the proteins identified by the MASCOT program, with the identity for both proteins and peptides equal to $100 \%$.

Protein abundance was quantified by spot densitometry analysis using ImageMaster 2D Platinum Software (GE Health Care, Little Chalfont-UK). The software used powerful algorithms for efficient spot detection, accurate spot quantification, and an accurate statistical comparison of spot density across gels.

\section{MicroRNA identification in silico}

The identified proteins were used to search for potential microRNAs (miRNA). miRNAs were predicted using the web-based computational software TargetScan, which is freely available at http://www.targetscan.org. In summary, by default, this program identifies conserved sites of target genes that match the seed region of each miRNA [22]. Predictions were ranked based on the predicted efficacy of targeting based on cumulative weighted context++ scores of the sites, which combine multiple features to build quantitative models of targeting efficacy and thus indicates how efficiently a given miRNA may target on mRNAs according to Agarwal et al. [23]. The identified miRNAs ranked as the top three candidates for a post-transcriptional control of each protein found as differentially abundant between treatments were chosen to validate via reverse transcription quantitative polymerase chain reaction (RT-qPCR). In addition, aiming to double-check the miRNA prediction performed via TargetScan, a second web-based computational software, miRmap [24], was used. In summary, this software is based on thermodynamic, evolutionary, probabilistic and sequence-based approaches to predict potential targets providing a miRmap score. We also used the Cytoscape NetworkAnalyzer Tool [25] to illustrate the mRNA-miRNA interaction of the top three candidates' miRNA. Illustrated interaction was based on context++ scores from the TargetScan program.

\section{Extraction of RNA enriched with miRNA and reverse transcription CDNA synthesis}

Extraction of RNA enriched with miRNA was performed by using a mirVana ${ }^{\text {ax }}$ isolation kit (Invitrogen, California, USA) following the manufacturer's instruction. The concentration of miRNA-enriched samples was estimated by a NanoVue ${ }^{\mathrm{rm}}$ Plus spectrophotometer (GE Healthcare, Freiburg, Germany) and their integrity was assessed through 1\% agarose gel electrophoresis. The reverse transcription of total RNA-miRNA enriched samples was performed by using the miScript II RT kit (Qiagen, Hiden, Germany) following the manufacturer's instruction. The abundance of both mRNA and miRNA was performed from the same cDNA sample to avoid possible bias due to differences in the extraction method.

\section{Quantitative real-time PCR analysis}

Quantitative RT-PCR (qPCR) was performed in a thermal cycler ABIPrism 7300 Sequence Detection Systems (Applied Biosystems, Foster City, CA, USA) using an miScript SYBR Green PCR Kit (Qiagen, Hilden, Germany). Primers were obtained based on the mature sequence of the identified miRNAs in the present study (Table 2). Mature sequences were obtained in the miRBase database [26], according to each miRNA name. Primers used for the mRNA (Table 3) were selected based on their efficiency and specificity. The amplification efficiency ranged from 0.90 to 0.99 . After amplification, a melting curve $\left(0.01{ }^{\circ} \mathrm{C} / \mathrm{s}\right)$ was used to confirm product purity. For the miRNA, due to its small size, the product of qPCR reaction was confirmed in $1 \%$ agarose 
Table 2 Primers used to measure the relative abundance of miRNA using qRT-PCR

\begin{tabular}{lll}
\hline miRNA & Mature ID & Primer sequence (5'-3') \\
\hline bta-miR-2899 & MIMAT0013857 & AGGCGGGCCGGGGTTGA \\
bta-miR-34a & MIMAT0004340 & TGGCAGTGTCTTAGCTGGTGT \\
bta-miR-449a & MIMAT0009320 & TGGCAGTGTATTGTTAGCTGGT \\
bta-miR-665 & MIMAT0009363 & ACCAGTAGGCCGAGGCCCCT \\
bta-miR-2349 & MIMAT0011884 & TGGCACTTCTGGTCTCAGACTCA \\
bta-miR-3120 & MIMAT0024572 & CACAGCAAGTGTAGACAGGCA \\
bta-nCRNA U6 & XR003033651 & GTGCTCGCTCGGCAGCAC \\
\hline
\end{tabular}

gel. The qPCR reaction consisted of three cycle parameters: $95^{\circ} \mathrm{C}$ for $3 \mathrm{~min}, 40$ cycles at $95^{\circ} \mathrm{C}$ for $10 \mathrm{~s}$, and $60{ }^{\circ} \mathrm{C}$ for $30 \mathrm{~s}$. The housekeeping gene used for the mRNA expression was the $18 \mathrm{~S}$, while the ncRNA-U6 was used for miRNA expression. No differences were observed $(P>0.05)$ for the expression of $18 \mathrm{~S}$ and ncRNA-U6 between treatments. The expression of both $\mathrm{mRNa}$ and miRNA was calculated using the $2^{-\Delta \mathrm{Ct}}$ method [27].

\section{Statistical analysis}

The intensity of the normalized abundance volume of each spot obtained by two-dimensional electrophoresis, as well as mRNA and miRNA expression, were analyzed by using a linear model including the fixed effect of RFI group. After the initial analyses, the residuals from the analysis of each variable were assessed for normality using the Shapiro-Wilk's test. The mRNA and miRNA expression data did not achieve normality, and it was transformed using $\log \left(2^{-\Delta \mathrm{cT}}\right)$. Least-squares means were estimated for the effect of RFI group. Results were deemed significant when $P<0.05$. All analyses were performed using the MIXED procedure of SAS 9.4 (Statistical Analysis System Institute, Inc., Cary, NC, USA).

\section{Results}

Difference in protein abundance in skeletal muscle of RFIhigh and RFI-low groups

Data from all nine animals from each experimental group were analyzed. The two dimensional proteomic analysis revealed proteins with molecular mass varying from 14.4 to $97 \mathrm{kDa}$ and the isoelectric point ranging from 3 and 10. Thirteen spots were found with different in abundance $(P<0.05)$ in the skeletal muscle between the RFI-Low (more efficient) and RFI-High (less efficient) groups (Additional file 1: Figure S1). From the 13 spots that had different abundance in skeletal muscle tissue of RFI-Low and RFI-High groups, three were able to be identified via mass spectrometry with high accuracy (100\% probability; Table 4). The failure to identify all the spots was due to the lack of a specific bovine protein databases that matched the data obtained in the present study and/or due to the percentage of protein identification probability lower than $100 \%$. From the three spots identified in the skeletal muscle tissue, two had higher abundance in RFI-High animals (spots 1 and 2), which were identified as Actin Alpha 1 and 14-3-3 Protein Epsilon. One spot had a higher abundance in RFI-Low animals (spot 3) and it was identified as Heat Shock Protein Beta 1 (Table 4).

From the three proteins identified to be differentially abundant among RFI groups, we further investigated the 14-3-3 Protein Epsilon and Heat Shock Protein Beta 1 due to their possible involvement in energy expenditure in skeletal muscle, and thus, may have an important role in feed efficiency. Actin Alpha 1 is a structural protein of the skeletal muscle and had no direct role with energy expenditure process in this tissue; thus, it was not further investigated.

\section{MicroRNA identification}

Aiming to identify potential miRNAs related to differentially abundant proteins among RFI groups, we performed in-silico analyses based on 14-3-3 Protein Epsilon and Heat Shock Protein Beta 1 genes. For this aim, we used two web tools, TargetScan and miRmap, which identified 24 and 16 miRNAs for Heat Shock Protein Beta 1, respectively, and, 129 and 171 miRNAs for 14-3-3 Protein Epsilon, respectively (Additional file 2: Table S1, Additional file 3: Table S2). From these, comparing booth programs, six miRNAs were in common for Heat Shock Protein Beta and 90 were in common for 14-3-3 Protein Epsilon. Moreover, based on the TargetScan context++ scores, the top three miRNAs identified to match conserved sites of the two target genes were selected (Fig. 1).

Table 3 Primers used to measure the relative abundance of mRNA using qRT-PCR

\begin{tabular}{llll}
\hline Gene Abbreviation $^{\text {a }}$ & Forward sequence (5'-3') & Reverse sequence $\left(3^{\prime}-5^{\prime}\right)$ & NCBI $^{\text {b }}$ \\
\hline YWHAE & TCCCTCTGAAGCAGGTTAG & GGAGAGGGAAGGAGAAGAAA & NM_174491.3 \\
HSPB1 & CACTCGCAAATACACGCT & TGACGGGAATGGTGATCT & XM_005225115.2 \\
$18 S$ & CCTGCGGCTTAATTTGACTC & AACTAAGAACGGCCATGCAC & NR_036642.1 \\
\hline
\end{tabular}

a YWHAE: Tyrosine 3-monooxygenase/tryptophan 5-monooxygenase activation protein; HSPB1: Heat Shock Protein family B member 1; 18S: ribossomal RNA

${ }^{b}$ National Center for Biotechnology Information database (www.ncbi.nlm.nih.gov) 


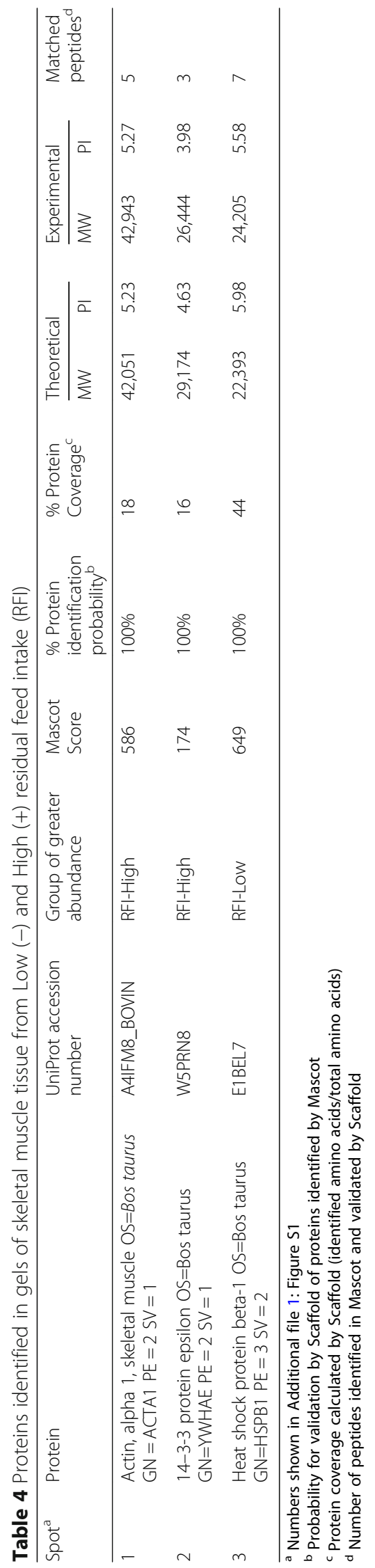



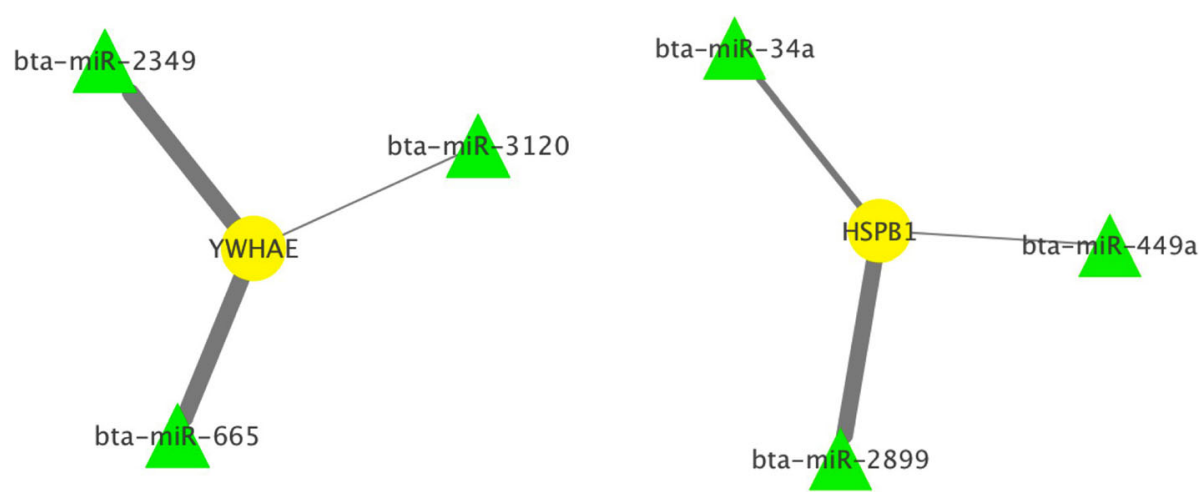

Fig. 1 Highly predicted miRNAs associated with HSPB1 and YWHAE. Cytoscape NetworkAnalyzer Tool was used to illustrate mRNA-miRNA interaction. Interaction was based on context++ scores from TargetScan program. Thicker edges mean lower context++ scores and thus stronger interaction. The mRNAs are yellow circle nodes and miRNAs are green triangle nodes

Difference in mRNA and miRNA involved in the synthesis of proteins the differentially abundant in skeletal muscle of RFI-high and RFI-low groups

Based on the results obtained from the proteomic study we further investigated the expression of miRNA in the skeletal muscle of both groups as a one of the possible mechanisms that led to changes in abundance of these proteins between the two groups. As miRNA acts post-transcriptionally, we also evaluated the expression of mRNA of genes that encodes the proteins that were found to be different in abundance between groups.

A greater mRNA expression of the HSPB1 $(P<0.01)$, which is the gene that encodes the Heat-Shock Protein Beta 1, was observed in the skeletal muscle of RFI-Low group (Fig. 2). Conversely, a greater mRNA expression of $Y W H A E$, which encodes the 14-3-3 Protein Epsilon, was observed in the RFI-High animals $(P<0.01$; Fig. 3).

With regard to the miRNAs revealed by an in-silico study to be involved in the post-transcription control of the Heat-Shock Protein Beta 1, no differences were observed in the expression of miR-449a $(P=0.82)$ in the skeletal muscle of the RFI-High and RFI-Low groups (Fig. 2). On the other hand, a greater expression of miR34a $(P<0.01)$ and miR-2899 $(P<0.01)$ was observed in the skeletal muscle of RFI-High group $(P<0.01$; Fig. 2$)$. For the top three miRNAs identified to be involved in the post-transcription control of 14-3-3 Protein Epsilon, only two of them were expressed in the skeletal muscle of the evaluated animals, whereas, no differences were observed for miR-3120 ( $P=0.43)$ between the RFI-High and RFI-Low groups (Fig. 3). However, a greater expression of miR-665 was observed $(P<0.01)$ for RFI-Low compared to RFI-High animals (Fig. 3).

\section{Discussion}

Differences in abundance of proteins related to energy expenditure in skeletal muscle

The results of the current study revealed a greater abundance of Heat shock protein beta 1 (HSPB1), also known as HSP27, in RFI-Low compared to RFI-High animals. The HSPB1 is a relatively small molecular chaperone protein associated to cellular development, differentiation and signal transduction [28]. Heat shock proteins (HSPs) are essential for normal cellular stress responses [29] and may serve to protect cells from otherwise damaging agents [30]. Heat shock proteins are also able to bind and stabilize unstable proteins and facilitate their correct assembly. In addition, HSPs enhance cell survival by interfering with cellular signal transduction pathways regulating apoptotic cell death [31]. Small HSPs (sHSPs) bind unfolded polypeptides, acting as an important defense mechanism against the formation of protein aggregates [32]. This can reduce the binding of the proteases responsible for the degradation of muscle fibers [33]. Down-regulation of HSPB1 may increase the degradation of muscle proteins such as actin and myosin [34], which may increase the rate of protein turnover in skeletal muscle.

Previous studies have investigated the proteome profile in divergent RFI animals and have found that RFI selection cause changes in skeletal muscle protein turnover [35], mitochondrial protein profile [36] and changes in energy metabolism of skeletal muscle [37]. According to Cruzen et al. [35], animals selected for reduced RFI have less protein degradation. Such conclusion may be supported by a greater cytoprotective role of the HSPs proteins that were found to be greater in abundance in the skeletal muscle of more efficient animals, which was observed by Grubbs et al. [36] (HSP70) and also in our study (HSP27). The protein degradation is an energetically 

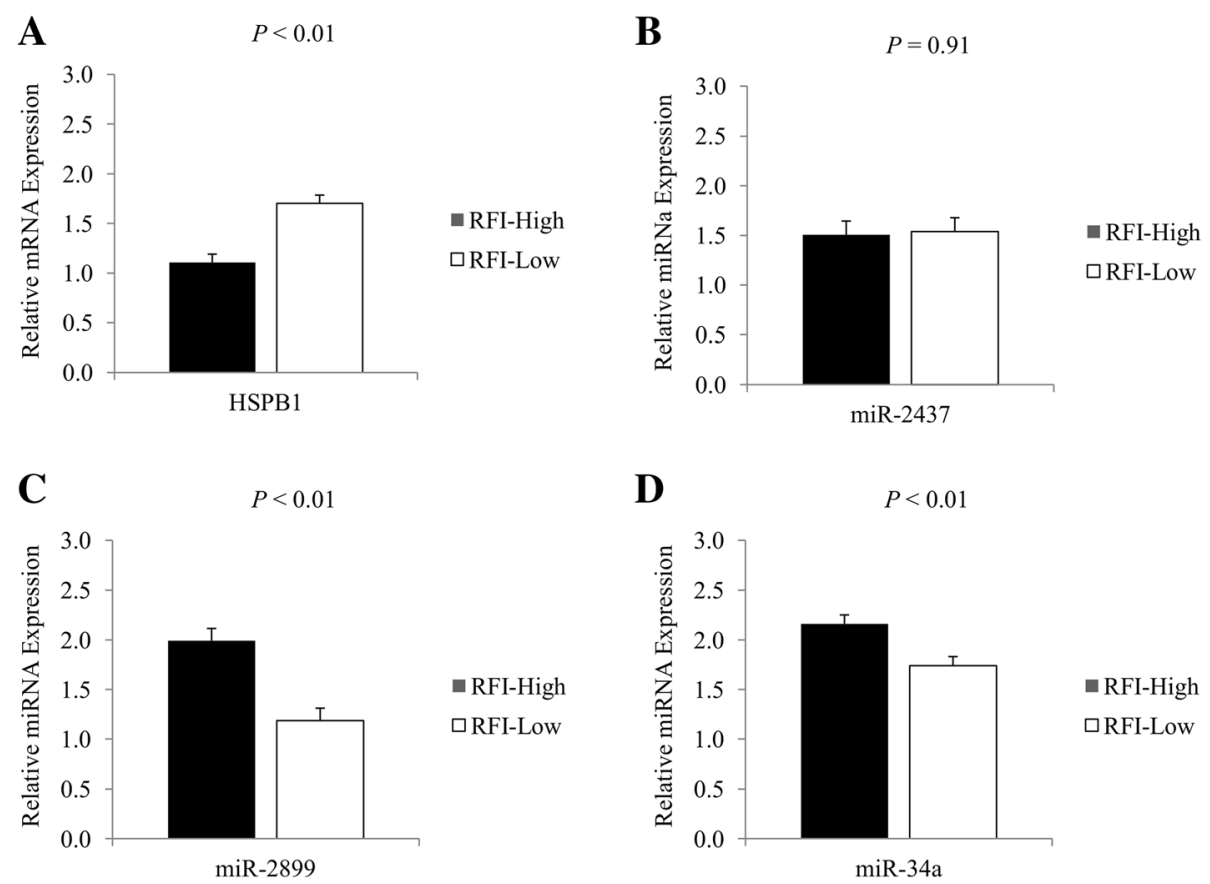

Fig. 2 Relative expression of the gene that encodes Heat-Shock Protein $\beta-1$ and the miRNAs founded to be involved in the post-transcriptional control of its expression. a Relative expression $\left(2^{-\triangle C T}\right)$ of HSPB1 to $18 \mathrm{~S}$ in skeletal muscle of RFI-High and RFI-Low Nellore cattle (RFI-High = 1.13; RFI-Low = 3.79; SEM = 0.36); b) Relative expression ( $2^{-\Delta c T}$ ) of miR-449a to ncRNA-U6 in skeletal muscle of RFI-High and RFI-Low Nellore cattle (RFI-High = 5.90; RFI-Low = 5.57; SEM =0.73); c) Relative expression $\left(2^{-\Delta c T}\right.$ ) of miR-2899 to ncRNA-U6 in skeletal muscle of RFI-High and RFI-Low Nellore cattle (RFI-High =9.49; RFI-Low =3.96; SEM = 1.05); d) Relative expression ( $2^{-\Delta c T}$ ) of miR-34a to ncRNA-U6 in skeletal muscle of RFI-High and RFI-Low Nellore cattle (RFI-High $=6.71$; RFI-Low $=2.81$; SEM =0.76). Differences were considered at $P<0.05$

expensive process because of the required ATP for the proteasome operation [35]. Thus, the decrease of protein degradation in low-RFI animals suggested by the greater abundance of HSPs in their skeletal muscle may lead to a lower energy requirement for maintenance of this tissue, contributing to their greater feed-efficiency. Thus, our results suggest that because more efficient animals (RFILow) showed a greater abundance of HSPB1, they may have a lower rate of protein turnover and consequently lower energy expenditure in the skeletal muscle compared to less efficient animals (RFI-High), which may contribute to their difference in feed efficiency.

In the current study, we found a greater abundance of 14-3-3 epsilon protein in RFI-High (less efficient) than RFI-Low (more efficient) animals. The 14-3-3 proteins are small $(\sim 30 \mathrm{kDa})$ acidic proteins found in all eukaryotic organisms, with seven isoforms in mammals. All 14-3-3 s are highly conserved both within and across species [38] and have the ability to bind a large number of proteins causing multiple effects in specific proteins [39], including

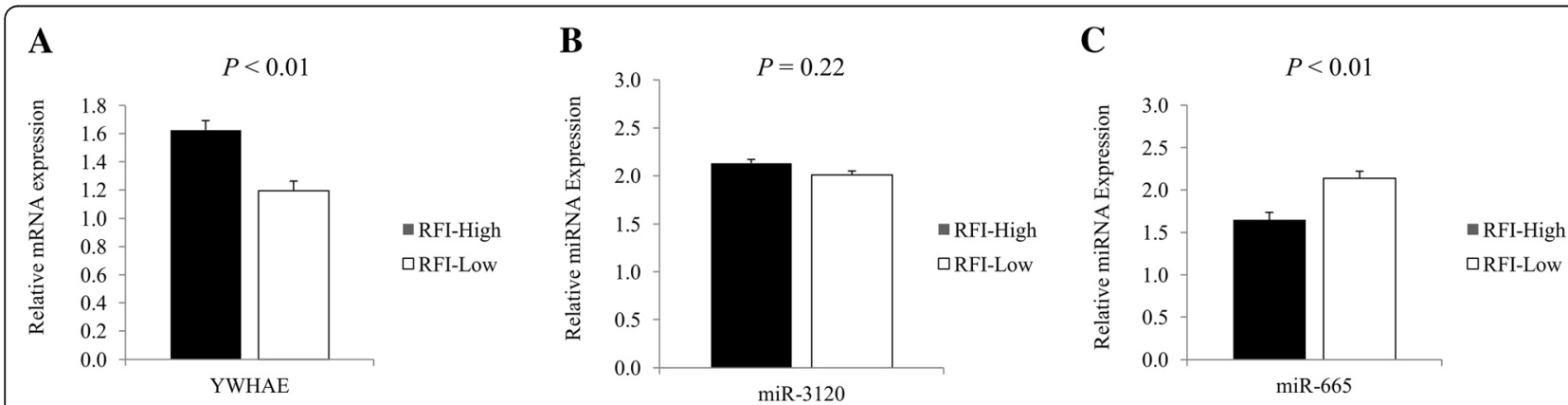

Fig. 3 Expression of the gene that encodes 14-3-3 Protein Epsilon and the miRNAs founded to be involved in the post-transcriptional control of its expression. a Relative expression $\left(2^{-\triangle C T}\right.$ ) of YWHAE to $18 \mathrm{~S}$ in skeletal muscle of RFI-High and RFI-Low Nellore cattle (RFI-High $=5.21$; RFI-Low $=3.02$; SEM $=0.35)$; b) Relative expression $\left(2^{-\Delta c T}\right.$ ) of miR-3120 to ncRNA-U6 in skeletal muscle of RFI-High and RFI-Low Nellore cattle (RFI-High $=4.96$; RFI-Low = 3.99; SEM = 0.59); c) Relative expression $\left(2^{-\Delta c T}\right.$ ) of miR-665 to ncRNA-U6 in skeletal muscle of RFI-High and RFI-Low Nellore cattle (RFI-High = 4.94; RFI-Low = 10.44; SEM =0.93). Differences were considered at $P<0.05$ 
kinases, phosphatases, and transmembrane receptors. One of the functions of 14-3-3 epsilon is its interaction with the insulin-like growth factor I receptor (IGF-I R) and with the insulin receptor substrate I (IRS-1) [40]. A study performed by Oriente et al. [41] found that insulin action was enhanced following 14-3-3 epsilon overexpression and was reduced upon antisense depletion of 14-3-3 epsilon, and that overexpression of 14-3-3 epsilon also induced a reduction in insulin degradation. Previous studies have found no association between systemic insulin level and RFI in beef cattle [42, 43], which suggests that high and low RFI beef cattle do not differ in insulin production. The difference observed in the current study on 14-3-3 epsilon highlight the possible increase in insulin action that could lead to a higher uptake of insulin by skeletal muscle cells and increased glucose uptake. Therefore, based on the results observed for the HSPB1, it is plausible to suggest that such an event may occur in RFI-High animals due to a greater energy expenditure in their skeletal muscle as a consequence of a greater protein turnover, as previously stated. This possible mechanism was highlighted in a previous study, where HSPB1-null mice showed changes in the abundance of 14-3-3 epsilon in their skeletal muscle [44].

Another process that strongly contribute to energy expenditure in skeletal muscle is mitochondrial proton leakage [45], which is caused by the presence of uncoupling proteins (UCPs) located in the inner membrane of mitochondria. The UCPs cause the pumping of protons from the mitochondrial intermembrane space back to the mitochondrial matrix decreasing the electrochemical gradient necessary to generate ATP [46]. Despite the relevant importance of UCPs for energy metabolism in skeletal muscle, studies have shown similar or slight differences in the mRNA expression of UCP2 and UCP3 $[12,47]$ neither for UCP2 and UCP3 protein abundance in skeletal muscle [47] among high and low RFI beef cattle. Collectively, the lack of major changes in UCPs mRNA expression and the absence of these proteins in the proteomic results of the current study, as well as in the proteome of isolated skeletal muscle mitochondria [36] in skeletal muscle leads us to believe that, although UCP proteins may affect the energy expenditure in skeletal muscle at a cellular level, it does not differ in beef cattle selected for feed efficiency by RFI.

\section{Identification of miRNAs as possible post-transcriptional control of the differentially abundant proteins}

MicroRNAs (miRNAs) have been reported as small noncoding RNA with a range from 18 to 23 nucleotides. The miRNAs act post-transcriptionally regulating gene expression by the target messenger (mRNA) in a sequence-specific manner, leading to either degradation of the target transcript and/or translational repression
[48]. Studies have reported the association of miRNA and feed efficiency and energy metabolism in pigs [18], and cattle [14], showing the importance of the miRNA in the control of energy metabolism and subsequent changes in feed efficiency.

In a recent study designed to identify the possible role of miRNA in the regulation of RFI, a total of 156 mature miRNA sequences were identified in the skeletal muscle of beef cattle contrasting RFI. Of these, one miRNA (bta-miR-486) was differentially expressed between low and high RFI beef cattle [49]. The authors also reported the insulin pathway as a main target pathway of the btamiR-486 in skeletal muscle being the protein kinase AMP-activated catalytic subunit alpha 1 (AMPK) in one of the targets. A study in pigs reported miRNAs associated with changes in energy metabolism between high and low RFI pigs [18]. Taken altogether, these studies highlight the involvement of miRNA in feed efficiency, likely by controlling energy utilization at the tissue level.

In our current study, after differential abundance of HSPB1 and 14-3-3 epsilon proteins in the skeletal muscle were identified between RFI-High and RFI-Low animals, we investigated why these difference may have occurred. We then evaluated the expression of candidate miRNAs that had possible involvement in the posttranscription modifications that resulted in changes in both proteins synthesis. As mentioned above, several studies have highlighted the importance of both proteins in the metabolism of skeletal muscle [44, 50-52]. However, to the best of our knowledge, this is the first study that investigated a possible molecular mechanism that may be responsible for the changes in the abundance of both proteins in skeletal muscle of beef cattle differently classified based on RFI.

Our results have shown a decrease of mRNA expression of HSPB1 in skeletal muscle of RFI-High (less efficient) compared to RFI-Low (more efficient) animals. Such a result is supported by the greater expression of miR-34a and miR-2899 in the skeletal muscle of RFIHigh animals, as both miRNAs have HSPB1 transcript as a target. The miR-34a has been reported to be involved with apoptosis [53] and myoblast proliferation and differentiation [54], while miR-2899 was already identified to be expressed in beef cattle intramuscular and subcutaneous fat [55]. From our in-silico analyses, bta-miR-2899 had the greatest context++ score and can also be predicted by the TargetScan and miRmap programs. Based on these gene and miRNAs expressions, we may explain the differences in the abundance of HSPB1 protein between RFI-High and RFI-Low animals, as well as show a possible mechanism by which this protein biosynthesis is controlled in beef cattle differing in feed efficiency. 
Another target mRNA that we have investigated in the current study was the YWHAE, which encodes the 14-33 protein epsilon. The mRNA expression of $Y W H A E$ was lower in the skeletal muscle of RFI-Low (more efficient) compared to RFI-High (less efficient) animals. This result may have occurred due to a greater expression of miR-665 in the skeletal muscle of RFI-Low animals. Such an observation likely explains the lower abundance of the 14-3-3 protein epsilon in RFI-Low compared to RFI-High animals. miR-665 has been reported to be differentially expressed during prenatal skeletal muscle development in pigs [56] and also expressed in cattle skeletal muscle [57]. This miRNA had the greatest context++ score (TargetScan) and one of the greatest miRmap scores, suggesting a strong interaction of $Y W H A E$ transcript. In our study, this miRNA is suggested to be associated with more feed efficient cattle.

The mechanisms of miRNAs controlling mRNA translation depend on the way miRNAs bind to their putative targets. A complete pairing (miRNA-mRNA) leads to a cleavage of the mRNA, while an imperfect binding might inhibit the translation $[15,58]$. In our study, even though bta-miR-2899 and miR-665 were strongly linked with their respectively targets, the in-silico analyses suggest an imperfect pairing. Thus, based on our in-silico and in vitro analyses, it is expected that bta-miR-2899 and miR665 may inhibit the translation of HSPB1 and YWHAE transcripts, respectively.

It must be emphasized that miRNAs have several different targets. Thus, the results herein obtained may be taken into consideration not only for the control of the biosynthesis of the proteins that were found to be differentially abundant in the skeletal muscle of both RFI groups, but also for the contribution of the miRNAs in the control of the biological process underlying the discrepancy in feed efficiency. Moreover, to the best of our knowledge, this is the first time the miR-665, miR$34 \mathrm{a}$, and miR-2899 were linked with feed efficiency in beef cattle.

\section{Conclusion}

This study revealed differences in the abundance of HSPB1 and 14-3-3 epsilon proteins in skeletal muscle of Nellore beef cattle divergently identified for RFI. These results suggest that differences in energy expenditure in the skeletal muscle may contribute to their difference in feed efficiency. Moreover, we have shown differences in the mRNA expression of the genes encoding both proteins, which seems to be post-transcriptionally controlled by miRNA. Finally, our data also highlight the possible role of miR-34a, miR-2899, and miR-665 in the biological process underlying discrepancy in feed efficiency in beef cattle. These results warrant further studies to elucidate the mechanisms of control of these miRNAs in energy metabolism to our better understanding of biological process associated with feed efficiency.

\section{Additional files}

\begin{abstract}
Additional file 1: Figure S1. Representative 2-dimensional gel image of skeletal muscle from a Nellore bull. Proteins are indicated by spot number, which corresponds to those identified as differentially abundant between the different RFI groups. Spot 1: Actin, alpha 1, skeletal muscle; Spot 2 : 14-3-3 protein epsilon; Spot 3: Heat shock protein beta-1. (TIF 372 kb)
\end{abstract}

Additional file 2: Table S1. Potential miRNAs related to Heat Shock Protein Beta 1 (HSPB1) identified via TargetScan and miRmap web tools. (DOCX $18 \mathrm{~kb}$ )

Additional file 3: Table S2. Potential miRNAs related to14-3-3 Protein Epsilon (YWHAE) identified via TargetScan and miRmap web tools. (DOCX $54 \mathrm{~kb}$ )

\section{Abbreviations}

2-DE: Two-dimensional electrophoresis; ACN: Acetonitrile; ADG: Average daily gain; BSA: Bovine serum albumin; BW: Body weight; BW ${ }^{0.75}$ : Metabolic body weight; CDNA: Complimentary DNA; DTT: Dithiothreitol; HSPB1: Heat-shock protein beta 1; IGF-I R: Insulin-like growth factor I receptor; IPG: Immobilized pH gradient; IRS-1: Insulin receptor substrate I; MADI - TOF: matrix-assisted laser desorption/ionization - time of flight; miRNA: micro RNA; mRNA: Messenger RNA; MW: Molecular weight; pl: Isoelectric point; PMSF: Phenylmethanesulfonyl fluoride; RFI: Residual feed intake; RTqPCR: Reverse transcription quantitative polymerase chain reaction; SDS: Sodium dodecyl sulfate; sHSPs: Small heat-shock proteins; YWHAE: Gene that encodes the 14-3-3 protein epsilon

\section{Acknowledgments}

Thanks to Dr. Nick Serão from the Department of Animal Science at lowa State University for his valuable contribution on the English proofreading and revision of technical terms used in the manuscript.

\section{Authors' contributions}

ECB, MSD, and MPG designed the research; ECB RSTR and WS performed the experiments, SFMB, MSD and SEFG, contributed with animal and research tools; ECB, RSTR, FFS, LLV and MSD analyzed the data, EBC, MPG, CJN, ED, LLV and MSD intellectually contributed to the content and wrote the paper. All authors read and approved the final manuscript .

\section{Funding}

This work was funded by the Instituto Nacional de Ciência e Tecnologia Ciência Animal (INCT-CA, Grant number 465377/2014-9), the British Council/ Coordenação de Aperfeiçoamento de Pessoal de Nível Superior (CAPES; Grant number 172728031), and CAPES PROEX 676/2018 (Grant number

23038.000839/2018-53). The funding agencies provided financial support that allowed the performance of the study and did not play a role in the study design, data collection, analysis, decision to publish, or manuscript preparation.

\section{Availability of data and materials}

All data is hosted at the Federal University of Viçosa-Brazil Repository and is freely available by contacting the corresponding author.

\section{Ethics approval}

All animals used in the current study were owned by the Instituto de Zootecnia-IZ/SP, which provided a written consent to use the animals for animal's use. Care and handling of all experimental animals were conducted under protocols approved by the Ethics Committee on Animal Use of the Instituto de Zootecnia (CEUA/IZ; Protocol 213-15), Nova Odessa, SP, Brazil, and in accordance with guidelines of State Law No. 11.977 of the State of São Paulo, Brazil.

Consent for publication

Not applicable. 


\section{Competing interests}

The authors declare that they have no competing interests.

\section{Author details}

'Department of Animal Science, Universidade Federal de Lavras, Lavras, MG Brazil. 'Department of Animal Science, Universidade Federal de Viçosa, Viçosa, MG, Brazil. ${ }^{3}$ Department of Veterinary Sciences, Universidade Federal do Vale do São Francisco, Petrolina, PE, Brazil. ${ }^{4}$ Centro APTA Bovinos de Corte, Instituto de Zootecnia, Sertãozinho, SP, Brazil. ${ }^{5}$ Scotland's Rural College, Edinburgh, UK. ${ }^{6}$ Department of Animal Science, Universidade Federal dos Vales do Jequitinhonha e Mucuri, Diamantina, MG, Brazil.

Received: 27 September 2018 Accepted: 7 June 2019 Published online: 17 June 2019

\section{References}

1. Herd R, Archer J, Arthur P. Reducing the cost of beef production through genetic improvement in residual feed intake: opportunity and challenges to application. J Anim Sci. 2003;81:E9-E17.

2. Baker SD, Szasz J, Klein T, Kuber P, Hunt C, Glaze J, Falk D, Richard R, Miller J, Battaglia R. Residual feed intake of purebred Angus steers: effects on meat quality and palatability. J Anim Sci. 2006;84:938-45.

3. Archer J, Reverter A, Herd R, Johnston D, Arthur P: Genetic variation in feed intake and efficiency of mature beef cows and relationships with postweaning measurements. In From the 7th world congress on genetics applied to livestock production. 2002.

4. Arthur PF, Renand G, Krauss D. Genetic and phenotypic relationships among different measures of growth and feed efficiency in young Charolais bulls. Livest Prod Sci. 2001;68:131-9.

5. de Barros Moreira Lemos NL, Flores Auge AP, Lunardelli JL, Brites Frade A, Frade $\mathrm{CL}$, de Oliveira AL, Ayroza Galvao Ribeiro PA, Aoki T. Optimizing pelvic organ prolapse research. Int Urogynecol J Pelvic Floor Dysfunct. 2007;18: 609-11

6. Herd RM, Arthur PF. Physiological basis for residual feed intake. J Anim Sci. 2009;87:E64-71.

7. Frayn KN. Metabolic regulation: a human perspective: John Wiley \& Sons; 2009.

8. Tizioto PC, Coutinho LL, Decker JE, Schnabel RD, Rosa KO, Oliveira PS, Souza MM, Mourão GB, Tullio RR, Chaves AS, et al. Global liver gene expression differences in Nelore steers with divergent residual feed intake phenotypes. BMC Genomics. 2015;16:1-14.

9. Fonseca LF, Gimenez DF, Mercadante ME, Bonilha SF, Ferro JA, Baldi F. Expression of genes related to mitochondrial function in Nellore cattle divergently ranked on residual feed intake. Mol Biol Rep. 2015;42:559-65.

10. Oliveira PSN, Cesar SM, Nascimento ML, Chaves AM, Tizioto PC, Tullio RR. Identification of genomic regions associated with feed efficiency in Nelore cattle. BMC Genet. 2014;15:100.

11. Weber KL, Welly BT, Van Eenennaam AL, Young AE, Porto-Neto LR, Reverter A, Rincon G. Identification of gene networks for residual feed intake in Angus cattle using genomic prediction and RNA-seq. PLoS One. 2016;11:e0152274.

12. Kelly AK, Waters SM, McGee M, Fonseca RG, Carberry C, Kenny DA. mRNA expression of genes regulating oxidative phosphorylation in the muscle of beef cattle divergently ranked on residual feed intake. Physiol Genomics. 2011:43:12-23.

13. Al-Husseini W, Chen Y, Gondro C, Herd RM, Gibson JP, Arthur PF. Characterization and profiling of liver microRNAs by RNA-sequencing in cattle divergently selected for residual feed intake. Asian Australas J Anim Sci. 2016:29:1371-82

14. Barendse W, Reverter A, Bunch RJ, Harrison BE, Barris W, Thomas MB. A validated whole-genome association study of efficient food conversion in cattle. Genetics. 2007;176:1893-905.

15. Bartel DP. MicroRNAs: genomics, biogenesis, mechanism, and function. Cell. 2004;116:281-97.

16. Ambros $V$. The functions of animal microRNAs. Nature. 2004:431:350

17. Herranz H, Cohen SM. MicroRNAs and gene regulatory networks: managing the impact of noise in biological systems. Genes Dev. 2010;24:1339-44.

18. Jing L, Hou Y, Wu H, Miao Y, Li X, Cao J, Michael Brameld J, Parr T, Zhao S: Transcriptome analysis of mRNA and miRNA in skeletal muscle indicates an important network for differential Residual Feed Intake in pigs. 2015, 5:11953.

19. Fidelis HA, Bonilha SFM, Tedeschi LO, Branco RH, Cyrillo JNSG, Mercadante MEZ. Residual feed intake, carcass traits and meat quality in Nellore cattle. Meat Sci. 2017;128:34-9.
20. Del Bianco Benedeti P, Detmann E, Mantovani HC, Bonilha SFM, Serão NVL, Lopes DRG, Silva W, Newbold CJ, Duarte MS. Nellore bulls (Bos taurus indicus) with high residual feed intake have increased the expression of genes involved in oxidative phosphorylation in rumen epithelium. Anim Feed Sci Technol. 2018;235:77-86.

21. Brasil. Regulamento da inspeção industrial e sanitária de produtos de origem animal [Regulation of Industrial and Sanitary Inspection of Animal Products]. Brasília, DF, Brazil (In Portuguese): Ministério da Agricultura, Pecuária e Abastecimento. 1997. https://www.saude.rj.gov.br/comum/code/ MostrarArquivo.php?C=NzU2NQ\%2C\%2C. Accessed 20 May 2017.

22. Lewis BP, Burge CB, Bartel DP. Conserved seed pairing, often flanked by adenosines, indicates that thousands of human genes are MicroRNA targets. Cell. 2005;120:15-20.

23. Agarwal V, Bell GW, Nam J-W, Bartel DP. Predicting effective microRNA target sites in mammalian mRNAs. eLife. 2015;4:e05005.

24. Vejnar CE, Zdobnov EM. miRmap: comprehensive prediction of microRNA target repression strength. Nucleic Acids Res. 2012;40:11673-83.

25. Shannon P, Markiel A, Ozier O, Baliga NS, Wang JT, Ramage D, Amin N, Schwikowski B, Ideker T. Cytoscape: a software environment for integrated models of biomolecular interaction networks. Genome Res. 2003:13:2498-504

26. Kozomara A, Griffiths-Jones S. miRBase: annotating high confidence microRNAs using deep sequencing data. Nucleic Acids Res. 2013;42:D68-73.

27. Schmittgen TD, Livak KJ. Analyzing real-time PCR data by the comparative CT method. Nat Protoc. 2008:3:1101.

28. Zhang Q, Lee H-G, Kang SK, Baik M, Choi Y-J. Heat-shock protein beta 1 regulates androgen-mediated bovine myogenesis. Biotechnol Lett. 2014;36: 1225-31.

29. Keady SM, Kenny DA, Ohlendieck K, Doyle S, Keane M, Waters SM. Proteomic profiling of bovine M. longissimus lumborum from crossbred Aberdeen Angus and Belgian blue sired steers varying in genetic merit for carcass weight. J Anim Sci. 2013;91:654-65.

30. Creagh E, Sheehan D, Cotter T. Heat shock proteins-modulators of apoptosis in tumour cells. Leukemia. 2000;14:1161-73.

31. Lomiwes D, Farouk M, Wiklund E, Young O. Small heat shock proteins and their role in meat tenderness: a review. Meat Sci. 2014:96:26-40.

32. Fischer D, Matten J, Reimann J, Bönnemann C, Schröder R. Expression, localization and functional divergence of aB-crystallin and heat shock protein 27 in core myopathies and neurogenic atrophy. Acta Neuropathol. 2002;104:297-304.

33. Carvalho ME, Gasparin G, Poleti MD, Rosa AF, Balieiro JCC, Labate CA, Nassu RT, Tullio RR, Regitano LCA, Mourão GB, Coutinho LL. Heat shock and structural proteins associated with meat tenderness in Nellore beef cattle, a Bos indicus breed. Meat Sci. 2014;96:1318-24.

34. Kim N-K, Lim D, Lee S-H, Cho Y-M, Park E-W, Lee C-S, Shin B-S, Kim T-H, Yoon D. Heat shock protein B1 and its regulator genes are negatively correlated with intramuscular fat content in the longissimus Thoracis muscle of Hanwoo (Korean cattle) steers. J Agric Food Chem. 2011;59:5657-64.

35. Cruzen SM, Harris AJ, Hollinger K, Punt RM, Grubbs JK, Selsby JT, Dekkers JC, Gabler NK, Lonergan SM, Huff-Lonergan E. Evidence of decreased muscle protein turnover in gilts selected for low residual feed intake. J Anim Sci. 2013;91:4007-16.

36. Grubbs JK, Huff-Lonergan E, Gabler NK, JC MD, Lonergan SM. Liver and skeletal muscle mitochondria proteomes are altered in pigs divergently selected for residual feed intake. J Anim Sci. 2014:92:1995-2007.

37. Fu L, Xu Y, Hou Y, Qi X, Zhou L, Liu H, Luan Y, Jing L, Miao Y, Zhao S, et al. Proteomic analysis indicates that mitochondrial energy metabolism in skeletal muscle tissue is negatively correlated with feed efficiency in pigs. In Scientific Reports. 2017:7:45291.

38. Bridges D, Moorhead GB. 14-3-3 proteins: a number of functions for a numbered protein. Science Signaling. 2004;2004:re10.

39. Porter GW, Khuri FR, Fu H. Dynamic 14-3-3/client protein interactions integrate survival and apoptotic pathways. In: Seminars in cancer biology: Elsevier; 2006. p. 193-202.

40. Craparo A, Freund R, Gustafson TA. 14-3-3 ( ) interacts with the insulin-like growth factor I receptor and insulin receptor substrate I in a phosphoserinedependent manner. J Biol Chem. 1997;272:11663-9.

41. Oriente F, Andreozzi F, Romano C, Perruolo G, Perfetti A, Fiory F, Miele C, Beguinot $F$, Formisano P. Protein kinase $C$-a regulates insulin action and degradation by interacting with insulin receptor Substrate-1 and 14-3-3€. Biol Chem. 2005;280:40642-9. 
42. Kelly AK, McGee M, Crews DH Jr, Fahey AG, Wylie AR, Kenny DA. Effect of divergence in residual feed intake on feeding behavior, blood metabolic variables, and body composition traits in growing beef heifers1. J Anim Sci. 2010:88:109-23.

43. Lawrence P, Kenny DA, Earley B, McGee M. Grazed grass herbage intake and performance of beef heifers with predetermined phenotypic residual feed intake classification. animal. 2012;6:1648-61.

44. Picard B, Kammoun M, Gagaoua M, Barboiron C, Meunier B, Chambon C, Cassar-Malek I. Calcium homeostasis and muscle energy metabolism are modified in HspB1-null mice. Proteomes. 2016;4:17.

45. Rolfe DF, Newman JM, Buckingham JA, Clark MG, Brand MD. Contribution of mitochondrial proton leak to respiration rate in working skeletal muscle and liver and to SMR. Am J Phys. 1999;276:C692-9.

46. Garlid KD, Jaburek M, Jezek P, Varecha M. How do uncoupling proteins uncouple? Biochim Biophys Acta. 2000;1459:383-9.

47. Kolath WH, Kerley MS, Golden JW, Shahid SA, Johnson GS. The relationships among mitochondrial uncoupling protein 2 and 3 expression, mitochondrial deoxyribonucleic acid single nucleotide polymorphisms, and residual feed intake in Angus steers. J Anim Sci. 2006;84:1761-6.

48. Bushati N, Cohen SM. microRNA functions. Annu Rev Cell Dev Biol. 2007;23: 175-205.

49. Oliveira PSN, Coutinho LL, Tizioto PC, Cesar ASM, de Oliveira GB, Diniz WJS, De Lima AO, Reecy JM, Mourão GB, Zerlotini A, Regitano LCA. An integrative transcriptome analysis indicates regulatory mRNA-miRNA networks for residual feed intake in Nelore cattle. Sci Rep. 2018;8:17072.

50. Picard B, Berri C, Lefaucheur L, Molette C, Sayd T, Terlouw C. Skeletal muscle proteomics in livestock production. Brief Funct Genomic. 2010;9:259-78.

51. Kleppe R, Martinez A, Døskeland SO, Haavik J. The 14-3-3 proteins in regulation of cellular metabolism. Semin Cell Dev Biol. 2011;22:713-9.

52. Mullins $C R$, Zerby HN, Fitzpatrick LA, Parker AJ. Bos indicus cattle possess greater basal concentrations of HSP27, alpha B-crystallin, and HSP70 in skeletal muscle in vivo compared with Bos taurus cattle1. J Anim Sci. 2016; 94:424-9.

53. Chang T-C, Wentzel EA, Kent OA, Ramachandran K, Mullendore M, Lee Kwang H, Feldmann G, Yamakuchi M, Ferlito M, Lowenstein CJ, et al. Transactivation of miR-34a by p53 broadly influences gene expression and promotes apoptosis. Mol Cell. 2007;26:745-52.

54. Wang G-q, Wang Y, Xiong Y, Chen X-C, Ma M-I, Cai R, Gao Y, Sun Y-m, Yang G-S, Pang W-J. Sirt1 AS IncRNA interacts with its mRNA to inhibit muscle formation by attenuating function of miR-34a. Sci Rep. 2016;6:21865.

55. Wang $H$, Zheng $Y$, Wang $G$, Li H. Identification of microRNA and bioinformatics target gene analysis in beef cattle intramuscular fat and subcutaneous fat. Mol BioSyst. 2013;9:2154-62.

56. Tang Z, Yang Y, Wang Z, Zhao S, Mu Y, Li K. Integrated analysis of miRNA and mRNA paired expression profiling of prenatal skeletal muscle development in three genotype pigs. Sci Rep. 2015;5:15544.

57. Sun J, Sonstegard T, Li C, Huang Y, Li Z, Lan X, Zhang C, Lei C, Zhao X, Chen $\mathrm{H}$. Altered microRNA expression in bovine skeletal muscle with age. Anim Genet. 2015;46:227-38.

58. Portnoy V, Huang V, Place RF, Li LC. Small RNA and transcriptional upregulation. Wiley Interdiscip Rev RNA. 2011;2:748-60.

\section{Publisher's Note}

Springer Nature remains neutral with regard to jurisdictional claims in published maps and institutional affiliations.

\section{Ready to submit your research? Choose BMC and benefit from:}

- fast, convenient online submission

- thorough peer review by experienced researchers in your field

- rapid publication on acceptance

- support for research data, including large and complex data types

- gold Open Access which fosters wider collaboration and increased citations

- maximum visibility for your research: over $100 \mathrm{M}$ website views per year

At $\mathrm{BMC}$, research is always in progress.

Learn more biomedcentral.com/submissions 